\title{
INFORMATION SURPLUS AS THE MODERN STAGE IN THE EVOLUTION OF INFORMATION ASYMMETRY
}

\section{Valeria Kornivska ${ }^{1}$}

DOI: https://doi.org/10.30525/978-9934-588-15-0-34

Abstract. In the networked information conditions triggered the misbalance of the transmission mechanism through which the information space exercises its effect. This has been partly due to the destructive processes in the system of interpersonal relations, and partly due to global transformation processes. Economic relations develop at the backdrop of systemic value disruption caused by the growing amount of information of questionable quality. Subjected to the removal of social filters from the information space, the public will become a perfect container for unlimited volumes of any information with a next to zero value, however the impact of this information will get stronger because of the undefined state of the social space, increasing information asymmetry. Recognizing the informational asymmetry as the basic condition for the emergence of society, the article presents the content of information asymmetry evolution, describes its current stage. Metodology: the combination of the information theory and logical and historical methodology. The study based on classical theoretical approaches to information asymmetry in an economic environment have been developed by Kenneth J. Arrow, George Akerlof, Michael Rothschild, Joseph Stiglitz, Michael Spence, Robert Shiller. The purpose of the article is to reveal the evolution of information asymmetry and to characterize its current stage on the basis of logical and historical methodology. The evolution of information asymmetry is a logical and historical process in which information asymmetry acquires new qualities different from the initial information asymmetry through objective and subjective information asymmetry over to information surplus and the development of global and monopolistic information asymmetry emerging from the concentration and monopolization of information by information giants and accompanied by the exasperation of bureaucracy and direct administration of economic and

\footnotetext{
${ }^{1}$ Doctor of Sciences (Economics), Senior Research Fellow, Institute for Economics and Forecasting of NAS of Ukraine, Ukraine

(C) Valeria Kornivska
} 
social processes both nationally and around the globe. The study demonstrates the phenomena introduced to the communication space together with the development of the networked information economy, such as desubjectivation, concentration and surplus of information. The study defined the growth factors for the information surplus, specifically the active generation of information in the backdrop of the crisis of professionalism; it characterizes the global monopolist information asymmetry as the special condition for economic activity in the context of networked information economy, which considerably promotes the growth of uncertainty for regular participants of economic interaction.

\section{Introduction}

The innovative development of the new information society constantly fills the economic and sociocultural space with new knowledge that needs to be processed and delivered to the end user, thus enabling the "new common sense" through making knowledge routinely used for the benefit of society.

Yet what is the way to go with the process of cognition and transfer of knowledge in a modern world where the socioeconomic space is filled not only with innovation information of positive value, but also with unstructured, contradictory, mutable and at times erroneous information streaming from multiple sources? The situation is further complicated by the fact that modern information transmission systems deliver data to the end user within the shortest possible time, virtually instantly, so the volume of information waiting to be processed is constantly growing, reducing at the same time the actual chances of putting it to a practical test, which fuels the constant increase in information asymmetry.

Once the social space started getting saturated by information, once it stopped being scarce, once telecommunication technology made it possible to significantly improve its mobility, social mechanisms started shifting towards imbalance and conflict, preconditioning tangible economic risks. The long-established value-based premises for economic communication began their transformation. For example, they exacerbated the problem of "principal vs agent," when the more informed party to an interaction corrupts data, creating a false information background in the context of a subjective information asymmetry. 
The first theoretical approaches to the analysis of information asymmetry in economics started emerging in the 1960-1970's, in the time when the social space experienced the growing volume of information to be analyzed and processed, and the economic space started inviting new information technology into its environment.

Classical theoretical approaches to information asymmetry in an economic environment have been developed by Kenneth J. Arrow [1, p. 941-973], George Akerlof [2, p. 488-500], Michael Rothschild, Joseph Stiglitz [3, p. 629-649], Michael Spence [4, p. 355-379; 5, p. 355-365], Robert Shiller [6]. The first ever mentioning of incomplete information in the economic science as an important condition for the interaction of economic agents was made in the work by K. Arrow, Uncertainty and the Welfare Economics of Medical Care [1, p. 941-973].

In the 1970 s, the problem of information asymmetry in economics, i.e. the situation where one participant of the interaction has more information than the other, started coming up in the discussions across both academic circles and the business environment. Following long-term research in this field, G. Akerlof and R. Shiller [6] concluded that in a market economy, the situation where one participant of the interaction is more informed than the other is completely natural. Information asymmetry is a prerequisite for an economic space; it is its basic component. The academics gave examples on how companies grow their businesses using the weaknesses of consumers, their vulnerabilities, which result from the incomplete information about the true motives of the manufacturers and the production environment. The authors claim, that the free-market system reveals and exploits our weaknesses automatically [6].

The asymmetric information theory made a great impact on the basic understanding of price balance and the optimal distribution of resources in economics. Moreover, it introduced important amendments to the system of corporate management, as the involvement in the production of the most (managers, workers) and the least (shareholders) informed parties drove the need to encourage company managers to manage the company effectively. This specific phenomenon of information asymmetry in a company with noticeable dispersion of corporate assets helped shift classical capitalism towards the domination of managers over business owners. "The corporations came to be run to profit its managers, in complicity if not conspir- 
acy with accountants and the managers of other corporations" [7, p. 8], i.e. bonus-driven managers became one of the factors of the present-day crisis.

In 2001, G. Akerlof, M. Spence and J. Stiglitz received the Nobel Prize in Economic Sciences for the analysis of markets with asymmetric information. Their classical works on the problems of information asymmetry were published in 1970 by G. Akerlof [2, p. 488-500], in 1973 by M. Spence [4, p. 355-379], and in 1976 by M. Rothschild and J. Stiglitz [3, p. 629-649]. In those works, the authors looked into the consequences of unfavorable selection in the product, labor and insurance markets. Further works researching into information asymmetry were centered on the analysis of moral risks, specifically the risk of defaulting on contract terms after entering into it; those were works by S. Grossman and O. Hart [8, p. 7-45], B. Holmström [9, p. 74-91], J. Mirrless [10, p. 3-21].

The classical works on the problems of information asymmetry view it as a factor of communication, formation of contractual relationship and delivery on the agreement terms when one of the parties to the economic interaction experiences explicit/implicit information deficit. The modern society of open data and transparent communications provides opportunities for overcoming information asymmetry and establishing economic relationships based on parity, whereby any party can obtain all the available information within the shortest time. And yet information asymmetry is not being overcome, but on the contrary, it is growing, developing, transforming. The evolution of information asymmetry is ongoing.

The purpose of the article is to reveal the evolution of information asymmetry and to characterize its current stage on the basis of logical and historical methodology.

\section{Information asymmetry in societies preceding the networked information economy}

Everything that makes up a human life has an informational aspect, specifically a person's perception of themselves as a personality, ideas about the world around them, the day-to-day activity, rules and mechanisms underlying the interaction with other people. Information asymmetry (IA) is the prerequisite of one's existence which a person brings to the world at birth, for a newborn baby has absolutely no idea about himself or the world around him, i.e. how it is built and which rules it obeys. At the same time, in 
a human's world, a newborn baby is one of its components whose basic life activities are known, and the mechanisms of upbringing and socialization are clear. In other words, the information about a human being is objectively defined in the context of the historical process of evolution of human and social life. On the other hand, each human emerges in this world with a tiny fraction of information concerning their existence, and that fraction relies on reflexes. This holds the meaning of basic information asymmetry (Figure 1) - the proportion of known to unknown information. The entire human life relies on the process of overcoming the information asymmetry through cognition.

It has been historically proved that the human's evolutionary aptness depends on the availability of true information about the world around. The reason for this is that the life expectancy and living conditions of the primitive man depended on the validity, accuracy of the information about the conditions of existence (such as the rules of behavior within and outside of the tribe, at hunting, in case of danger, etc.) acquired from his parents and

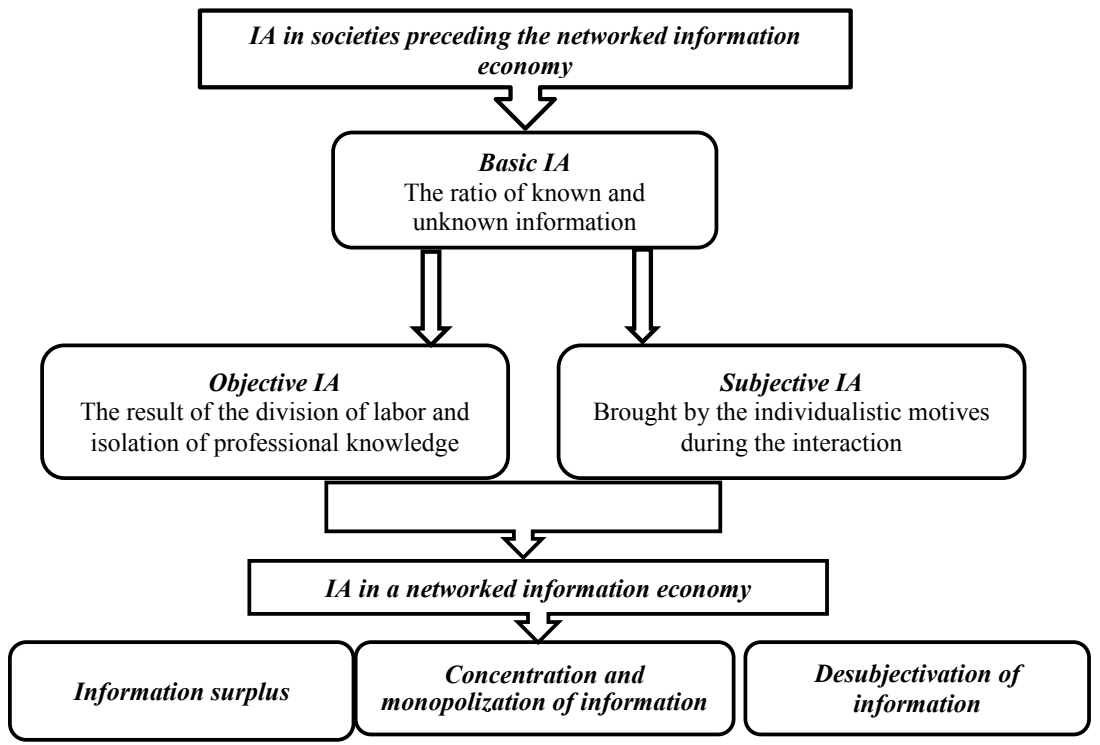

Figure 1. Evolution of information asymmetry

Source: based on the author's research 
on his trust in them as the primary source of information. The evolution of the human species, the world exploration processes, the expansion of philosophical and scientific knowledge all prove the crucial role the information quality and trust play as the fundamental factors for human development.

In Aristotle's classical understanding, a statement is true if and only if it corresponds to something that exists [11]. Therefore, the truth is the relevant information about an object that is being characterized from the perspective of trustworthiness.

Trustworthiness can be achieved through a theoretical replication that ensures the correspondence to the reality. Trustworthy information is perceived as real, not requiring any additional verification. Information accuracy is the philosophical, scientific and practical imperative that underpins the interaction between economic entities. Trust as an interaction factor can only be formed in the setting of trustworthiness which ensures confidence in the behavior of the other entity.

According to the definition by A. Grytsenko, Doctor of Economics, trust is the attitude to entities and institutions, which corresponds to the degree of confidence in the adequacy of their behavior through understanding their way of action in various forms of mutual activities towards the achievement of a certain goal, without realizing the terms for cost compensation, equivalence and profitability [12, p. 17].

Trust is an evolutionary element. The ability to analyze and verify information could only develop in response to the formation of an information base in the human consciousness in the process of work, and also due to the emergence of distrust. The search for the truth, for trustworthy information is a dynamic process of removing the controversy within the phenomenon of trust vs distrust.

Based on the theoretical findings of modern psychology, we acknowledge that a human arrives in this world with a trust potential, which ensures certainty and psychological confidence. The more a person grows emotionally and socially, the more often they question themselves about the sufficiency and completeness of the information they have at hand. Therefore, the person faces the distrust towards the completeness of their own knowledge and its accuracy. It inspires them to further cognize and fathom the world and the role of a human in this world. The person, being aware of their knowledge limitations and embarking on the path of search, therefore trusts that their 
knowledge is incomplete, thus making their first step on the way to removing the conflict between trust and distrust, as this is trust in the initial distrust. Socrates' classical imperative, "I know that I know nothing," is translated into trust in distrust. The process of cognizing the truth, acquiring trustworthy information about the subject of learning, making the comprehensive, complete, practically true replication of the subject removes the conflict between trust and distrust in cognition, whereby the distrust towards the completeness and trustworthiness of the available information drives the research activity, which results in the acquisition of complete, true, trustworthy information.

The process of cognition and search for the truth includes the initial trust that transforms into distrust, but a special kind of distrust that presents a system of methods and instruments for mastering the subject and becomes a factor for removing the conflict between trust and distrust by means of receiving new, trustworthy, practically true knowledge [13, p. 16-23].

On the one hand, the asymmetry of information space is objective, since the world unknown to the human, the truth that has not been put to practice will always be vaster than the known world. On the other hand, the scientific, methodological and practical tools for processing the information inside each subject are limited, so there is a demand for professionals who would provide help with gathering, processing and delivering trustworthy, practically true information to the end user, this reducing the information asymmetry.

Therefore, the objective asymmetry of the information space brings up the next level of information asymmetry which we call objective (Figure 1), the one that develops as the natural result of division of labor that led to the emergence and establishment of various crafts and trades, separation and institutionalization of professions and introduction of a special kind of information - professional information, which makes a competitive edge and is closed to the members of other professions. Being closed to "others," it naturally brings about the need to trust the work results of a professional whose work-related activity is institutionally closed to other market players. Historically, a profession or professional activity relies on and calls for trust. In its turn, the social space demands professional knowledge and opinion, i.e. professional information. This historically and objectively created a dependency between the development of trust and the professional knowledge (the totality of professional skills and functions), which appeared and intensified as a result of objective information asymmetry. 
On the other hand, there is the subjective information asymmetry (Figure 1) that is the result of different information awareness at the start of an interaction, which is formed due to individualistic motives, such as the wish to keep, retain, conceal information, give false information etc. to achieve the desired communication effect. The subjective asymmetry can be minimized by ethical norms of professionalism whose touchstone influence was mentioned way back by Luther who came up with the need for the moral qualification of secular professional activities [14]. A U.S. sociologist T. Parsons considered professions a structural element of the modern society, which demonstrates how economical motives are restrained by professional ethics, and the institutional code of one's professional sphere curbs the selfish interest of the individual. T. Parsons argued that not all individuals and social groups turn to the free market in a bid to satisfy their selfish interests, such a social group is professionals. One of the key traits of a professional is the lack of egoistic interest, which contrasts him with the so-called "businessman." A professional does not see himself as a person pursuing his own profit, rather he is concerned with his clients and science [15, p. 34-46].

In the system of social institutes, professionalism and professional activities have fundamental importance, since they are the enablers of a space of trust in the economic interaction system. To turn to the services of an economic agent means to value his professionalism and trust him. Among the psychological indicators of professionalism, apart from cognitive and innovative capabilities, there are also the motivational ones, including professional values, ideals, mentalities; the understanding of the significance of a profession; a professional mindset and the possession of ethical norms of one's profession, being able to match the criteria of professionalism. The connection between cognitive, innovative and motivational factors of professionalism reflect the unity of economic and ethical criteria, compliance with which creates a space of trust in the system of economic relations, which consequently maximizes the effect of the interaction between the subjects and improves their innovative abilities.

Today's society calls for adequate professionalism that acts as a necessary facilitating link between a subject and the information space. The operational environment in information economy is strikingly different from the environment of a capitalistic state. 


\section{Information asymmetry in a networked information economy}

In his description of the underlying characteristics of the new society, Manuel Castells wrote, "The term 'information society' emphasizes the role of information in society. But I argue that information, in its broadest sense, e.g. as communication of knowledge, has been critical in all societies, including medieval Europe which was culturally structured, and to some extent unified, around scholasticism, that is, by and large an intellectual framework... In contrast, the term 'informational' indicates the attribute of a specific form of social organization in which information generation, processing, and transmission become the fundamental sources of productivity and power, because of new technological conditions emerging in this historical period" [16].

In the modern high-tech-dominated society, the abundance of sources of information, the unstructured nature of information and its vast volumes create the problem of information asymmetry in a new sense: concentration, desubjectivation, surplus of information (Figure 1). When subjected to these processes, information turns from the condition for the development of postindustrial paradigm, with its largely humanistic principles, into a socio-humanitarian instrument; the information revolution and innovative growth stopped serving each other's purposes, whereas the oversaturation of the information space takes place in the setting of the dwindling financing of the general innovative growth.

Prior to the crisis of 2009, the spending on research and development work (R\&D) used to grow steadily at around $7 \%$ per year. The data published in the Global Innovation Index 2016 report indicate that throughout 2014 , the expenditures on $R \& D$ across the world increased only by $4 \%$. This was the result of the slowdown in the economic growth in countries with emerging markets and the reduction of $R \& D$ spending in high-income countries [17]. According to the Global Innovation Index 2016, in 2015, despite the somewhat greater overall investment in $\mathrm{R} \& \mathrm{D}$, the business environment still was marked with downtrends [18].

At the same time, according to forecasts, investment in IT hardware, software, services, telecommunication and personnel - i.e. everything that can be jointly called the "infrastructure" of the digital universe and telecommunications - is expected to grow $40 \%$ in the period between 2012 and 2020 . Consequently, the cost per gigabyte (GB) over that period will likely fall from $\$ 2.00$ to $\$ 0.20$ [19]. 
Between 2005 and 2020, the volume of digital information will increase 300 -fold, from 130 exabytes to 40,000 exabytes or 40 trillion gigabytes (more than 5,200 gigabytes per each man, woman and child). Digital information will keep doubling each two years until 2020 [19]. Therefore, the increase in the size of the digital space is clearly ahead of the general innovation growth in the world, thus driving the information surplus (Figure 1), which is brought about by both the reduced cost of new information in the social interaction systems and its diminished value for an average consumer of the social space.

Today we can see the asymmetric impact of the information environment on the society and people through the concentration of information in the systems of global operators (Figure 1). In such circumstances, the subjects of information space (media, Internet operators) are free to manipulate information streams; they can receive, systemize, create, distribute information with the given size and quality, blow "information bubbles,» take an active part in information wars, while staying completely incognito and free from any responsibility.

The mobility of information distribution makes it even harder to reveal its responsible source. These processes of the desubjectivation (Figure 1) of the information space are directly related to the inflation of the value-based component, with the degrading of traditional, basic institutions that cement together and drive social interaction. On top of that, the lack of information responsibility is an actual reason for the withering of the need for economic freedom.

The desubjectivation of the information space makes the information separate itself from the object that emitted it to assume an independent life-purpose form and possibly affect the processes behind the interaction between the subjects, without revealing the sources of its origin, being an independent, a priori factor causing the effect of interaction. It directly affects the formation of trust/distrust, but not only in the context of the subject of interaction, but also in its own context. Therefore, in today's context, the classical understanding of how trust develops in connection with the information received from (about) the subject of the interaction requires an amendment to the view of the special role of the information space which has its own phenomenological nature.

The effect of the information space is currently controversial, not least due to the transitional state related to the fact that the crucial role of infor- 
mation as an asset in today's reality is not self-evident for the entire global economic space. Along with developed, innovation-driven countries, there are other countries that develop slowly, where innovations shun real economy, besides, there are also innovative-stagnating countries.

This means that the global space for absorbing innovative information is by no means homogeneous; institutionally saturated sections exist alongside voids and gaps. The latter can be observed in economies where innovations are consumed in a reduced form. In certain African countries, the digital world is represented largely by mobile banking [20, p. 61-81], whereas digital technology in production are omitted in the African economic practices. For such countries, the world of innovations is often the world of abstractions that hardly ever influences either economic or social growth. Indeed, mobile banking services in Africa have recently demonstrated rapid growth. However, the welfare of an average African unlikely depends on having a mobile account that can be used through a series of mechanical moves that neither require a high level of knowledge and skills nor affect the income level, as it only helps organize spending and payments. The use of innovative technology in such societies does not spur the economic growth, as the innovations used are mainly consumer-grade, and so: a) do not require any special education; b) do not change the consumer's social status; c) do not stimulate social growth; d) do not generate further innovations. The use of information as an asset in this case has virtually zero economic and social effect for such countries (yet a significant economic effect is enjoyed by multinational corporations that produce mobile and landline phones and by phone carriers).

As C. Perez argues, such state is to be expected in the context of the cyclical growth of economic systems: each technological revolution, before it can be considered such, goes through a maturity phase that can last for a while, so many innovations do not get traction for a long time [21, p. 33]. Despite the obviously uneven distribution of modern innovations, they, however, keep being generated, cementing global economic and socioinstitutional imbalances.

The ideology of the modern world has nurtured a specific global climate with the need for the constant, continuous generation of information, which spreads from the field of innovations all over the areas of socioinstitutional space; meanwhile, within the areas of regular operation of the subjects, it 
is fostered by the growing uncertainty that calls for the intensification of information streams, when quality is replaced with quantity.

In response to the disablement of value-based filters, these processes give rise to the information oversaturation (information glut) of the modern world, in which colossal volumes of unstructured information simply wander in space, generating information surplus. C.G. Jung gave the following description of the current information state: "We have become rich in knowledge, but poor in wisdom» [22, p. 9].

Today's people live in the state of deep lack of internal personal confidence and uncertainty in the outside world; humanistic ideals, put at the top of the list, in effect do not overcome this socioinstitutional imbalance, but instead make it worse, demonstrating individualism reduced to opportunism, focused on the achievement of "humanism for the self," thus downplaying its fundamental objectivity. The overriding of objectivity expands to all areas of social consciousness, whereas the information space becomes a platform for fulfilling the motives of self-centered subjects who are driven by formally humanistic maxims. That is why the modern world sees the development of the unprecedented tension between the external and internal, between objective and subjective reality. The information space loses its principles of objectivity and trustworthiness, since the subjects of interaction view information as a tool for pursuing their own individualistic motivations.

Another controversial topic of the modern day covers the social transformations that underpin the existence of a modern economic subject; its operating activity is a continuous process of gathering and transmitting professional and personal information within social media that become a basic element of adaptation to the environment of an information-driven society, specifically the need for the constant generation of innovative information.

The Pew Research Center, which monitors trends in the Internet activity of Americans, reports significant diversity in the ways people use social media for searching for information and interacting with others. The majority of Americans say they get news from social media. Americans use social media for professional purposes and for a mental break during work; for looking for a job and talking to their colleagues [23]. Therefore, any information need can be solved through social networks.

In view of the loss of trustworthiness in real communications, subjects more often than not turn to virtual communication, becoming its victims 
and champions at the same time. Today, networks play a crucial role in the emerging lack of personal freedom, their main threat lying in their being actively used for astroturfing [24, p. 571-587] - the manipulation of public opinion or creation of an artificial public opinion. So the specifics of an information society show themselves in the contradiction between the unlimited opportunities for getting the information that a person needs to develop, and the destructive effect caused to the socioinstitutional space by the content of information streams. The inconsistencies of the formal humanism in an information society create conditions for an information and humanitarian crisis - the crisis of the lack of freedom for a modern man in the context of the unlimited influence of information.

The modern society confronted the humankind with the problem of information surplus contrasted with the lack of its trustworthiness and objectivity. While information was presented on printed media, it used to be a relatively rare resource, and its trustworthiness used to be ensured by public authorities, which were in charge of educational, scientific, technical and information standards and disciplines. As soon as the Internet came to be the primary source of information, the common availability was now a benefit at the price of bias, opportunism and often fallacy, which, based on experience, cannot be persecuted or at least prevented. According to a recent sociological survey conducted in Ukraine (2017), the most popular sources of information are the following: for $42 \%$ of respondents - national TV channels, for $19 \%$ - online news websites; as for printed materials, national press $-3 \%$, local press $-4 \%$ [25].

In 2017, the researchers at the Massachusetts Technological University undertook a study on the effect that the online encyclopedia Wikipedia causes on scientific knowledge [26]. The study demonstrated that ideas published in Wikipedia are now increasingly used in scientific literature: the articles from the encyclopedia affect around each 300 words in relevant magazine publications. The researchers concluded that, apart from Wikipedia, any other online knowledge storage could increasingly influence the problems outlines in scientific works.

At the same time, it bears noting that the knowledge provided in Wikipedia is often of biased, controversial nature, sometimes outright erroneous. This raises the question about the quality of the scientific knowledge that is based on such information source. 
The classical motto of the Enlightenment, "Dare to know," trust your own knowledge, is getting transformed in the modern backdrop of the increasing uncertainly of the economic, social and information spaces. The trends in the development of information systems indicate that the incoming information requires thorough verification, thus multiplying transactional costs. Today's information is often manipulative by nature, whereby the complex system of unstructured messages manipulates the consciousness of both economic agents and the society in general.

The major problem of today's information systems is now to provide the sociocultural, economic and political space with accurate information the true information that creates the environment for a communication balance, which means equal opportunities for the subjects of interaction and the minimization of the asymmetry of the socioinstitutional space through the use of the services of true professionals.

On the one hand, the system of economic connections is neutral towards moral and ethical problems, since it does not cause any direct influence on the processes behind the development of value-based reference points in a person, but on the other hand, the system of economic interaction provides the most vivid reflection of the institutional and value-based phenomena, so for that reason exactly, when studying professionalism and its transformations, we analyze the deep-laid quality of the modern socioinstitutional development and its context in terms of values.

\section{Crisis of professionalism}

Under current conditions, professionalism has been displaced from the hierarchy of values, and this shows not only in the ethical aspect, but also in the functional, qualification one. Let us point out the following factors for the crisis of professionalism [27, p. 68-72]:

1. The modern information glut leads to the situation where the period for processing and efficient use of information is getting shorter, whereas the amount of incoming information is constantly growing. An increasing number of professionals who are jointly called "knowledge workers"1 have to add numerous operations (both inherent and not inherent to their trade) to their work, which significantly reduces productivity and creative potential.

${ }^{1}$ A term coined in 1960 s by Peter Drucker, a theorist of management, to describe intellectual workers whose job is related to information processing. 
2. A modern professional remains in the strategic state of imbalance due to the intensification of information asymmetry of the social space which originates from the constant updating of professional requirements and tasks of an average professional who is forced to take part in a permanent chase of new information. In other words, to keep up with the changes, one must acquire new professional information every 18 months. Back in the Industrial Age, changes were slow, so the knowledge acquired at school and during further education was valuable for a longer period of time. In the Information Age, any knowledge tends to get outdated. What one learned during the long education journey is important, but not as important as how fast one can learn, change, and adapt to new information. In this context, an absolutely logical question arises: how long, deep and efficient response one can offer to the stream of complex structured, multidisciplinary information arriving from outside?

3. The detachment of professionalism from the institutional environment of the middle class, which was largely due to global transformational processes and the increasing social stratification. The ability to do highly skilled work is what is most often named as the main objective criterion of the middle class, apart from the income level. The Russian Public Opinion Research Center conducted a survey in 2008, where respondents had to name five characteristics of the middle class. Only $14 \%$ of them mentioned that a member of the middle class should be a professional [28]. This means that in the public consciousness, the connection between these highly important institutions is damaged, which shifts the social value priorities.

4. The disruption of closed markets that used to be based on family business involving the experience of many generations; this is due to the socioinstitutional space being dominated by the ideology of short-term effects, which is incompatible with becoming a true professional (either from a functional or ethical perspective).

5. The expansion of the global labor migration, which is detrimental to the principle of being of use at home, i.e. the fundamental importance of the stability of a socioinstitutional environment for professional fulfillment and growth. The institution of professionalism is equally deeply affected by the global large-scale migration of low-qualified workforce with its attributive and symbolic impact on the overall professional climate (the unwillingness to work well, to be responsible for one's work). 
Pursuing professional activities in today's reality is associated with profound value transformations of systemic quality. Nowadays, information glut leads to the situation where the period for processing and efficient use of information is getting shorter, whereas the amount of incoming information is constantly growing.

This can only mean that under current conditions, the world is going through a crisis of information combined with a crisis of professionalism. Information requires to be organized in the system of professional knowledge, yet its exponentially growing amount is wandering in space due to the limited physical, mental and emotional abilities of professionals to capture it. On the other hand, the processing of a colossal volume of information impacts creative and professional performance. Still, the socioinstitutional space is badly in need of professional opinions and expert knowledge.

According to the research results by IDC $^{2}$, as of today less than $0.5 \%$ of the entire globally available digital information has been processed. Despite the rise of information security businesses, less than $20 \%$ information is secure. By 2020, developing markets will have outperformed the developed ones in the amount of generated data, yet information security will remain at a low level, which will create additional risks [19].

The information surplus not only undermines established systems of economic interaction, but also deform the subjects themselves, cripples fundamental institutions underlying the society.

\section{Monopolization of information}

The problem of the oversaturation of the information space also has another side of the coin, the monopolization of information. On the one hand, for an average participant of an economic interaction the uncertainty, risks, information asymmetry are constantly growing. On the other hand, this drives the processes of accumulation and reallocation of information in the system of supranational information giants. They have the information strictly systemized and structured, as its obvious purpose is the establishment of global regulation or even control.

\footnotetext{
${ }^{1}$ International Data Corporation (IDC) is a multinational research and consulting company founded in 1964 whose primary business is studying the global market of information technology and telecommunications.
} 
In April 2010, British cybersecurity experts announced that Apple gadgets, such as iPhone and iPad, not only tracked the user's location and stored the location history, but also sent the systemized information over to Apple. Google also records user information, such as search queries and user's IP addresses; text of emails; viewed and downloaded videos; user's geographic location; details of ads reviewed within Google's advertising network; details of friends in social media. In summer 2010, publications came out reporting that Google systematized information about $75 \%$ of its users, the information being private, such as preferences, personal mail, search history, contacts. Over 2018, the global media network Facebook was repeatedly involved in scandals related to the leakage of users' personal details which were then provided to interested third parties for modeling human behavior based on the evaluation of communication in social networks.

In autumn 2017, the global network Facebook announced that users must upload photographs of their faces in order to prove that they are live people and not robots. Therefore, if prior to that communication via social networks used to provide the benefit of anonymity, now it is about identification and the outright gathering of personal information.

Another example of the monopoly of information is the attack on bank secrecy and the global-level recording of financial information by FATF, followed by the efforts against the usage of cash that are being undertaken today across the globe. This means that given the ban on cash payments, global financial regulation authorities will have the complete information about the financial status, expenses, benefits, travels, marital status, cultural background, etc. of any subject. Private life stops being qualified as such, as it becomes accessible to a broad range of people and organizations. Therefore, today we see the formation of the global monopolistic information asymmetry as a special phenomenon. It develops in a networked information economy through the active gathering and concentration of information in the system of global information, financial, regulating operators; along with the emergence of global centers of information power which, by monopolizing the information space, exacerbate the uncertainty experiences by regular participants of the information space.

The modern age is the age of big data which was made possible thanks to the technology allowing to analyze huge amounts of data characterized 
by tremendous physical volume, high speed and diversity. Large by quantity and unstructured by quality, information streams need to be integrated and analyzed, and this gives rise to such business activity as data monetization earning by analyzing information in the context of specific tasks, usually the optimization of business processes in order to boost the client's profit. Companies providing monetization services are in a certain sense information monopolists, as they possess great amounts of confidential data on the workflow management within the company they analyze. At the output, this information can change the configuration of the client's business operation in any way, limited only by the professional ethics of the staff employed at the data monetization company. Among the problems addressed by such companies are sales growth, client retention, consumer anomaly detection, network reach expansion, online advertisement, transaction identification [29]. To analyze the client's activity, they need access to accounting data, CCTV, employee monitoring systems, in-store consumer behavioral patterns, etc. Using the latest technology, the acquired information is then categorized to record the history and create relevant company operation models, etc. In reality, this translates into a partnership of a third-party professional information monopolist who knows how to operate the acquired information using state-of-the-art IT products with a client who has vast amounts of information but is unable to utilize it efficiently.

The monopolization of information as part of the information asymmetry in the new economics can also be observed in the cutting-edge digital baking products. Let us quote McKinsey analysts who believe that today we must make a "'no regrets' move to prepare for a digital and data-driven world" [30]. This world will benefit from a significant potential of permanent institutional changes potentially leading to bifurcating trends and narrowing down the opportunities for the social space to adjust to these processes, thus initiating profound transformations in the economic space. In extreme cases, information surplus can lead to the complete demolition of the fundamental structuring potential of institutions.

\section{Conclusions}

We define the evolution of information asymmetry as a logical and historical process in which information asymmetry acquires new qualities different from the initial information asymmetry that develops as a rela- 
tion between the known and unknown parts of human perception; through objective and subjective information asymmetry that results from the institutionalization of professionalism, isolation of professional knowledge and individualistic motives for the interaction of subjects; over to information surplus which is an excess of information needed to make economic and social decisions that overloads information channels, unbalances communication processes and gives reason for the increase in uncertainty and the development of global and monopolistic information asymmetry emerging from the concentration and monopolization of information by information giants and accompanied by the exasperation of bureaucracy and direct administration of economic and social processes both nationally and around the globe.

\section{References:}

1. Arrow, Kenneth J. (1963). Uncertainty and the welfare economics of medical care. American Economic Review, vol. 53, 941-973.

2. Akerlof, G. (1970). The market for lemons: Quality uncertainty and the market mechanism. The Quarterly Journal of Economics, 89, 488-500.

3. Rothschild, M. and Stiglitz, J.E. (1976). Equilibrium in competitive insurance markets: An essay in the economics of imperfect information. The Quarterly Journal of Economics, 80, 629-649.

4. Spence, A.M. (1973). Job Market Signaling. Quarterly Journal of Economics, 87, 355-379.

5. Spence, A.M. (1974). Competitive and Optimal Responses to Signals: Analysis of Efficiency and Distribution. Journal of Economic Theory, March, 355-379.

6. Akerlof George A., Shiller, Robert J. (2015). Phishing for Phools: The Economics of Manipulation and Deception.

7. Pfaff, W.A. Pathological Mutation in Capitalism. International Herald Tribute, 2002, September 9, 8 .

8.Grossman, S. and Hart, O. (1983). An analysis of the principal-agent problem. Econometrica, 51, 7-45.

9. Holmström, B. (1979). Moral Hazard and observability. Bell Journal of Economics, 10, 74-91.

10. Mirrless, J.A. (1999). The theory of moral hazard and unobservable behaviour: Part I. Review of Economic Studies, 66, 3-21.

11. Stepanovich, V (2018). History of Philosophy. A lecture course in two volumes. Vol. 1. Historical types of classical philosophy.

12. Grytsenko, A.A., Artyomova, T.I., Krychevska, T.O. et al. (2012). The institution of trust in the coordinates of the economic space-time: monograph. Kyiv: National Academy of Sciences of Ukraine, the Institute of Economics and Forecasting.

13. Kornivskaya, V. (2009). Information quality as a factor of trust. Economic theory, 4, 16-23. 
14. Veber, M. (1905). Protestant ethics and the spirit of capitalism. Retrieved from: https://www.e-reading.mobi/bookreader.php/106518/Veber_Maks_Protestantskaya_etika_i_duh_kapitalizma.html

15. Parsons, $\overline{\mathrm{T}} .(193 \overline{9})$. The Professions and Social Structure. Parsons T. Essays in Sociological Theory (Revised Edition). New-York The Free Press, 1966, 34-46.

16. Castells, M. (1996). The information age: economy, society and culture. Retrieved from: Politzone. The portal of political sciences. http://politzone.in.ua/index.phpid=211

17. Global Innovation Index (2016). Retrieved from: http://www.wipo.int/ publications/en/details.jsp?id=4064\&plang $=\mathrm{RU}$

18. Global Innovation Index (2017). Retrieved from: https://www.globalinnovationindex.org/

19. Gantz, J. and Reinsel, D. (2019). The digital universe in 2020: Big Data, Bigger Digital Shadows, and Biggest Growth in the Far East, IDCI VIEW. Retrieved from: https://www.emc.com/collateral/analyst-reports/idc-the-digital-universe-in-2020.pdf

20. Kornivska, V. (2012). Trust and the information environment. The institution of trust in the coordinates of the economic space-time: monograph. Grytsenko A.A., Artyomova T.I., Krychevska T.O. et al. Kyiv: National Academy of Sciences of Ukraine, the Institute of Economics and Forecasting.

21. Perez, C. (2011). Technological revolutions and financial capital: the dynamics of bubbles and golden ages. Carlota Perez. Translated from English by F.V. Mayevsky. Moscow: Delo. The Academy of National Economy, 33.

22. Jung, C.G. (1991). The archetype and the symbol. Moscow.

23. Social Media Update (2016). Retrieved from: http://www.pewinternet. org/2016/11/11/social-media-update-2016/

24. Cho, C.H., Martens, M.L., Kim, H., \& Rodrigue, M. (2011). Astroturfing Global Warming: It Isn't Always Greener on the Other Side of the Fence. December, Volume 104, Issue 4, 571-587.

25. Research \& Branding Group: the Ukrainians draw information mainly from two sources (2017). Retrieved from: https://newsnetwork.tv/news/research-brandinggroup-ukraincy-cherpayut-informaciyu-preimushestvenno-iz-dvuh-istochnikov.html

26. Thompson, N., \& Hanley, D. (2018). Science Is Shaped by Wikipedia: Evidence from a Randomized Control Trial. Retrieved from: https://papers.ssrn.com/sol3/papers. cfm?abstract_id=3039505https://papers.ssrn.com/sol3/papers.cfm? abstract_id=3039505

27. Kornivskaya V. (2010). A crisis of values - a crisis of professionalism a crisis of trust. Economic theory, 3, 68-72.

28. The official VCIOM website (2008). Retrieved from: https://wciom.ru/ index.php?id $=236 \&$ uid $=9842$

29. Buslov, Ye. (2014). Data monetization in the age of big data. Retrieved from: http://www.cnews.ru/reviews/ppt/2014_12_04/2_Buslov.pdf

30. Dietz, M., Lemerle, M., Mehta, A., Sengupta, J., and Zhou, N. (2018). Remaking the bank for an ecosystem world. Retrieved from: //www.mckinsey.com/ industries/financial-services/our-insights/remaking-the-bank-for-an-ecosystemworld? cid=other-eml-nsl-mip-mck-oth-1711-nts\&hlkid=6572589a19ba4941ad0a dc7e46d64675\&hctky=2979573\&hdpid=95036f25-f56c-4d8c-9f10-9acb840fe8f5 